\title{
Reflets
}

Revue ontaroise d'intervention sociale et communautaire

\section{Maison La Paix : c’est quoi?}

\section{Carmelle Dugas}

Volume 4, numéro 2, automne 1998

Personnes vivant avec une incapacité

URI : https://id.erudit.org/iderudit/026233ar

DOI : https://doi.org/10.7202/026233ar

Aller au sommaire du numéro

Éditeur(s)

Reflets : Revue ontaroise d'intervention sociale et communautaire

ISSN

1203-4576 (imprimé)

1712-8498 (numérique)

Découvrir la revue

Citer cet article

Dugas, C. (1998). Maison La Paix : c'est quoi? Reflets, 4(2), 191-194.

https://doi.org/10.7202/026233ar

Tous droits réservés (C) Reflets : Revue ontaroise d'intervention sociale et communautaire, 1998

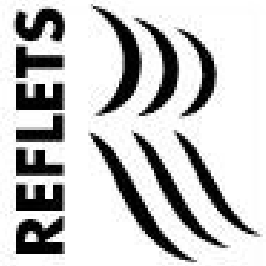

Ce document est protégé par la loi sur le droit d'auteur. L'utilisation des services d'Érudit (y compris la reproduction) est assujettie à sa politique d'utilisation que vous pouvez consulter en ligne.

https://apropos.erudit.org/fr/usagers/politique-dutilisation/ 


\section{Maison La Paix : c'est quoi?}

Carmelle Dugas, f.d.1.S., Sudbury

La Maison La Paix constitue une interrogation pour plusieurs personnes. Dans cet article, je tenterai d'y répondre, tout en partageant avec vous les fruits de l'expérience de ceux et celles qui oeuvrent à Maison La Paix.

La Maison La Paix est une demeure située au 303 de la rue Cedar, en plein coeur de Sudbury. C'est une maison bien ordinaire qui peut accueillir quatre personnes infectées par le virus du sida et désireuses de trouver une atmosphère de calme, de sérénité et d'amour. Les services offerts à Maison La Paix ont pour but de créer une ambiance familiale et d'assurer une qualité de vie possible à des personnes vivant une grande insécurité, condamnées qu'elles sont à vivre dans l'incertitude perpétuelle de leur maladie et à affronter la mort.

Comment pouvons-nous parler de qualité de vie chez des personnes qui attendent la mort? Nous ne pouvons rien sur la durée de notre vie, mais nous avons tout à dire sur la façon de la vivre. Lorsqu'on approche une personne atteinte du sida, on ne pense pas à une maladie ou une crise médicale de la santé. On regarde une personne qui souffre et qui a besoin de nous. Avec elle, nous luttons pour la vie avec tout ce que cela comprend.

\section{Qu'avons-nous à offrir à ceux et celles qui décident de vivre à la Maison La Paix?}

Comme toute personne atteinte d'une maladie qui menace les 
fondements même de l'existence, les résidents de Maison La Paix ont besoin de courage pour continuer à vouloir vivre, jour après jour, dans la douleur et avec le sentiment d'être un fardeau pour la communauté. Le courage dans leur combat est donc une des premières valeurs que les professionnels de la santé doivent soutenir. C'est un énorme défi, car la société tend à cacher, sinon à nier leur souffrance et suggère à ceux qui sont atteints de cette maladie incurable, de démissionner peu à peu de la vie.

La technologie et la médecine modernes offrent des services hors pair. Nous avons acquis un contrôle indéniable sur plusieurs maladies. Cela est formidable! Mais ces progrès techniques et médicaux engendrent simultanément une confusion sur la frontière entre ce qui est «naturel» et ce qui est «artificiel». Quand une personne ne produit plus, elle est parfois traitée comme un ventilateur défectueux qu'on jette au rebus. La science colore notre vision du monde mais il faut continuer à reconnaitre l'existence de réalités humaines fondamentales qui échapperont toujours à notre contrôle.

Marcher avec quelqu'un dans sa vie de souffrance, cela ne se fait pas sans amour. Nous avons tous un besoin fondamental: celui d'aimer et d'être aimé. Je dirais que les personnes atteintes du sida en ont encore plus besoin, car elles souffrent souvent de l'exclusion, du rejet, de l'abandon et de l'isolement. Ils perdent leurs amies et amis et, parfois, leurs propres familles les rejettent.

\section{De quel amour peut-on aimer ces personnes?}

Aujourd'hui, le mot amour est utilisé à toutes les sauces. L'amour est souvent considéré comme une recette miracle, un produit instantané. L'amour que nous voulons offrir aux résidants de Maison La Paix s'imprègne d'accueil, de solidarité, de soutien et de soins selon les besoins. Il vise à favoriser le bien-être intégral des personnes. Nos attitudes sont remplies de pardon et de miséricorde et se manifestent par une présence respectueuse, 
attentive et exempte de jugement. Nous côtoyons des personnes atteintes dans leur chair et dans leur être qui ont besoin de se dire à d'autres, dans un climat de confiance et d'acceptation. Dans la relation soignants-soignés, la tendresse et la compassion sont nécessaires. Toutes ces manifestations permettent la naissance d'une nouvelle force qui donne au malade, jour après jour, le courage de continuer sa lutte pour la vie.

\section{Comment les résidants de Maison La Paix réagissent-ils aux soins qu'ils reçoivent?}

J'aimerais partager avec vous quelques impressions recueillies lors d'entrevues avec les résidants. À ma question : «Qu'avez-vous à dire de Maison La Paix, votre chez-vous?», voici ce qu'ils m'ont répondu :

Pour moi, ce qui importe c'est l'accompagnement. Si quelqu'un s'assoie avec moi, m'écoute, m'encourage et me montre, par ses attitudes, que je suis aimé et accepté, je ressens un regain de vie et, malgré ma souffrance, je me sens revivre (un résidant).

Depuis mon arrivée à Maison La Paix, ma vie a pris tout un autre tournant. Des années durant, je ne savais pas d'où viendrait mon prochain repas ni où je reposerais ma tête le soir. Tout ce qui pour moi était une lutte journalière est devenue une sécurité que j'ai apprise à apprécier (un résidant).

Ma vie était décousue. Les liens avec ma famille et mes enfants étaient brisés. Je me sentais seul et abandonné et je ne voulais que la mort. Aujourd'hui, j'ai repris contact avec ma famille et mes enfants. Le rêve de plusieurs années est devenu une réalité.

En entendant de telles réflexions, nous réalisons que nos efforts n'ont pas été vains et que nous avons atteint bien modestement notre objectif. 
Je vous ai parlé des services offerts aux résidants. Mais ce trajet n'est pas à sens unique. Ceux qui dispensent les services en sont aussi bénéficiaires. Le ministère de se pencher sur la vie des autres est une mission très significative. Il est échu à chacun de nous par notre baptême, et n'est pas l'apanage de ceux et celles qui oeuvrent dans le domaine de la santé. Tous, nous sommes des guérisseurs. Chaque fois que nous nous penchons sur une personne afin de répondre à ses besoins, nous réalisons notre vocation de chrétiens et participons à l'œuvre de Jésus-Christ. Ceci est d'un grand réconfort. De plus, les malades, spécialement ceux atteints de maladies incurables, nous donnent, en retour, un surcroît de courage. En les voyant lutter avec ténacité, nous recevons la force d'affronter nos propres difficultés. Nous nous disons que s'ils peuvent lutter avec courage, au-delà de toute espérance, comment ne pourrions-nous pas, à plus forte raison, continuer notre route malgré les embûches.

Je voudrais dire un mot sur le privilège d'accompagner une personne durant sa maladie, et ce, jusqu'à sa mort. De voir la beauté d'une vie qui se transforme et qui se prépare au dernier voyage est véritablement un privilège. On en est souvent ébloui.

Ce trajet nous permet de découvrir ensemble où sont les vraies valeurs. Et ça, c'est un beau cadeau!

J'aimerais terminer ce texte par une citation extraite du livre de JeanVanier intitulé Toute personne est une histoire sacrée (1994). Il écrit :

Il n'y a pas de différence entre un être humain et l'autre. Nous sommes tous habités par le Seigneur. [...] Dans notre cheminement dans la vie, nous découvrons que le chemin de la paix ne consiste pas à monter vers la lumière dans une recherche d'une certaine puissance, mais c'est à descendre vers le petit, vers celui ou celle qui est faible.

Le paradoxe de la vie veut que tour à tour nous soyons ce petit, ce faible. Et c'est peut-être dans la maladie que nous faisons preuve de notre plus haute éducation: celle de diplômé à l'université de la vie. Imaginons cette vie, Si on Injectait Davantage d'Amour! (SIDA). 